\title{
Monitoring and Assessment Based on Ecological Sites
}

\section{By Jason W. Karl and Jeffrey E. Herrick}

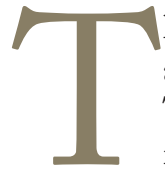

he importance of rangeland monitoring and assessment (hereafter RMA) generally is accepted. This is evidenced by the emphasis on robust monitoring programs at national (e.g., the Natural Resources Conservation Service Natural Resources Inventory), regional (e.g., range-wide monitoring of sage grouse habitat), and local (e.g., allotment-level monitoring within the Bureau of Land Management and US Forest Service) levels despite tightening budgets. However, the importance and benefits of RMA based on ecological site potential is less well understood.

The modern concept of an ecological site describes the potential vegetation communities that could occur on a site (states and phases) and the natural and human-caused processes that produce shifts from one phase to another and transitions between states. ${ }^{1}$ This concept evolved from that of the "range site," which described a unique climax plant community that would occur in an area in the absence of disturbance (i.e., Clementsian succession). The range concept was broadened to include multiple successional pathways and to describe the ecological and management processes that lead to changes both within and among plant community states (i.e., different successional pathways) and different plant community phases (i.e., communities within states). ${ }^{2}$

An ecological site provides a standard reference for land management, research, and monitoring. The ecological site description informs managers as to what kinds of changes can be expected in response to management or disturbance and provides a reference for the interpretation of RMA data. It also informs managers about ecological potential in terms of vegetation composition and vegetation-dependent uses (e.g., grazing, wildlife habitat). In other words, the ecological site determines what is possible, the current state determines what is realistic, and the phase within a state conveys the current conditions and likelihood of future transitions.

The concept of ecological sites and their current implementation via ecological site descriptions and associated geographic information system (GIS) spatial data layers provides a scalable framework for RMA. In addition, there are many practical uses of ecological sites for designing RMA programs and collecting and analyzing data from them. In this paper we describe an RMA framework based on ecological sites and present examples for several current and potential applications.

\section{A Framework for Monitoring and Assessment} A recently published framework for organizing, synthesizing, and applying ecological knowledge to land management consists of five elements ${ }^{3}$ (Fig. 1). Ecological sites are at the core of this framework because they are based on long-term ecological potential (i.e., climate, soils, and topographic setting) that provides useful information over the time frame of land management. Ecological sites also are widely accepted and used by resource management agencies. This framework, however, could also be applied using other land classification systems based on ecological potential (e.g., Terrestrial Ecological Units $\left.{ }^{4}\right)$.

The state-and-transition model (STM) for each ecological site is integral to the framework because it aids in identifying management strategies in the near term, specifically to 1) maintain systems in desired states or community phases; 2) move systems from one state to other, more desirable states; and 3) identify knowledge gaps. ${ }^{5}$ STMs also are useful for identifying processes that are likely to cause vegetation changes and predicting how affected plant communities will change. From this information it is possible to select ecosystem indicators that are sensitive to the expected changes.

In this framework, RMA systems measure change in land condition relative to its potential. Indicators of ecosystem function and status derived from RMA data, in conjunction with STMs, are used to interpret plant community changes in response to management and anticipate transitions between states. Rather than limiting the focus of RMA to a single objective (e.g., forage production, cover of perennial grasses), RMA within an ecological-site framework allows an area to be evaluated against its potential to provide an array of ecological functions. 


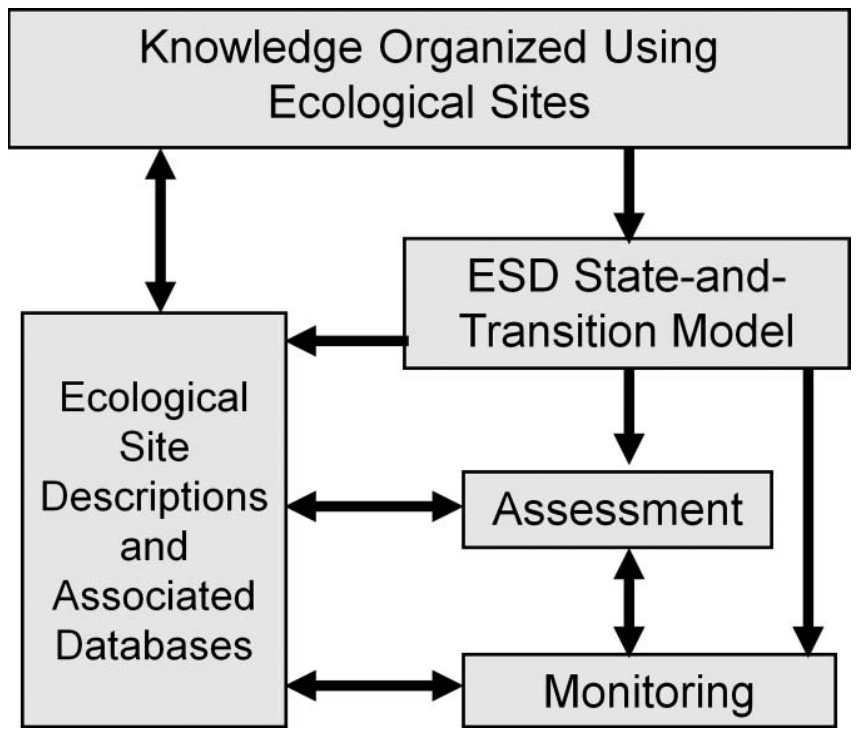

Figure 1. Herrick et al.'s ${ }^{3}$ framework for organizing, synthesizing, and applying knowledge of rangeland ecosystems based on ecological sites.

\section{Using Ecological Sites for Monitoring and Assessment}

There are several ways in which ecological sites can be used for RMA, including those following the framework in Figure 1 and others that take a different approach.

\section{Current Uses of Ecological Sites for Monitoring and Assessment}

One of the most common current uses of ecological sites for RMA is as a means of stratifying (or subdividing) a landscape for sampling. The primary role of stratification is to improve the ability to detect change by minimizing variability within, and maximizing variability between, strata. In RMA, strata should be defined based on areas having 1) the potential to produce similar types of vegetation and 2) similar responses to management and disturbance. Because ecological sites are defined based on soils and climate, they fulfill both of these criteria. Additionally, because soils and climate are relatively constant over the time span of most monitoring programs, ecological sites are expected to be a relatively stable means of stratification (but see discussion on climate change below).

One example of the use of ecological sites for stratification in RMA is from the Bureau of Land Management's (BLM) Winnemucca Field Office, Nevada. BLM staff in Winnemucca followed a three-step process to create RMA programs for livestock grazing allotments and wild horse and burro herd management areas. First, they stratified each landscape using the Natural Resources Conservation Service (NRCS) Soil Survey Geography (SSURGO) soil map units linked to ecological sites. A challenge that Winnemucca Field Office staff faced in using ecological sites for stratification was that the SSURGO map units, in many instances, did not resolve individual ecological sites. By definition,

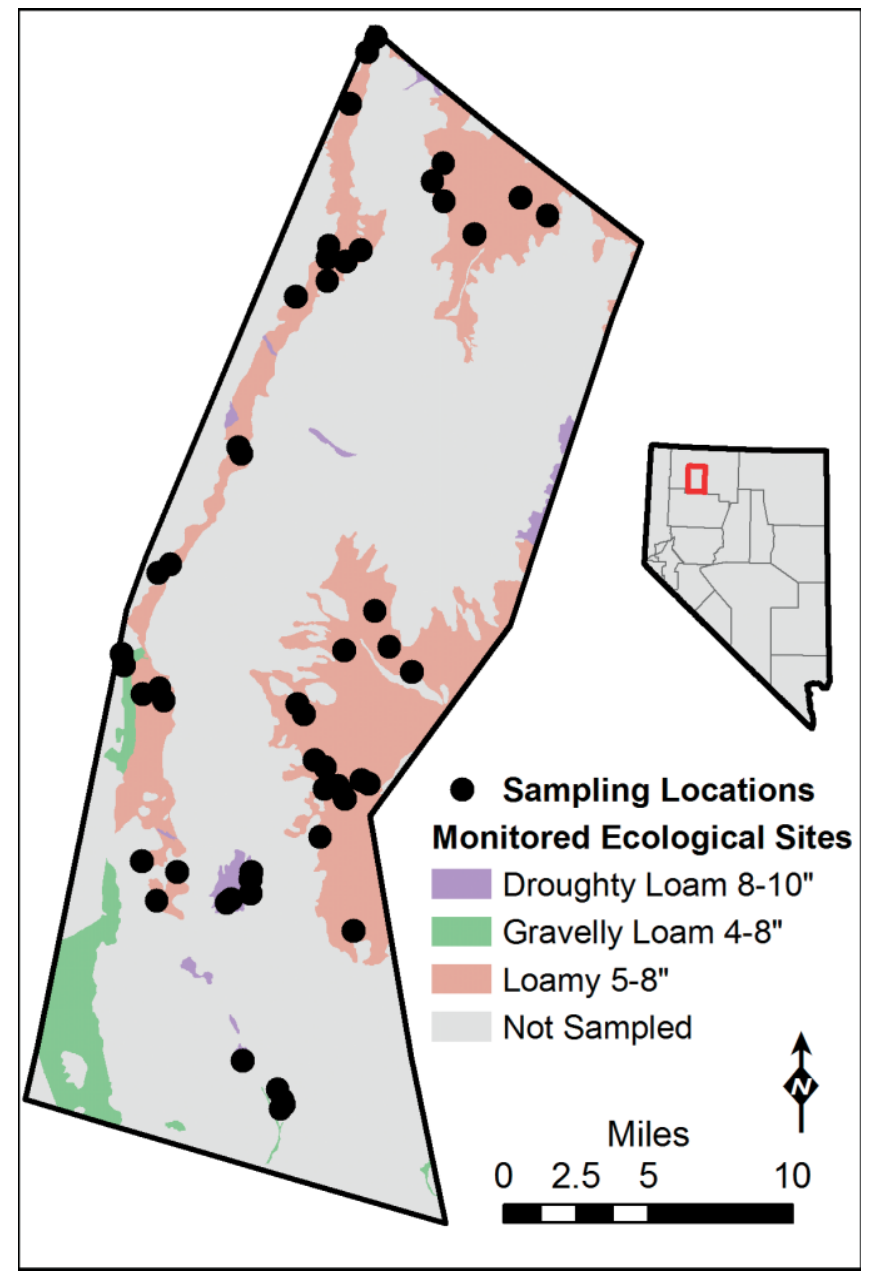

Figure 2. Example of using ecological sites as a means of stratifying a monitoring area for field-based sampling. Staff from the Bureau of Land Management's Winnemucca Field Office selected sample locations within a herd-management area by ecological site (shaded green and yellow polygons). Note that density of sample locations varied by ecological site based on expected use of the sites by wild horses.

each soil type supports a single ecological site, but often two or more soil types (i.e., soil map unit components) occurred in the same general region and were mapped together in a single map unit as an association. In these cases, a single soil map unit might contain multiple ecological sites because the exact spatial locations of the component soils within the unit occur at a scale finer than that of the soil mapping. For the second step, they randomly selected point locations within each soil map unit, generating a greater number of locations than they intended to measure. Finally, each sample location was evaluated using aerial photography, and when necessary, a site visit, to determine its ecological site. This process continued until enough points within each ecological site were identified for sampling (Fig. 2).

Ecological sites also are used to select and interpret indicators for RMA. The states and phases in an STM are described in terms of their vegetation composition and sometimes dynamic soil and soil-surface properties. STM 
transition narratives (i.e., management and disturbance events and processes) explain the mechanisms by which transitions to alternative states occur., ${ }^{5,6}$ This information can be used to identify indicators that link observable vegetation patterns to the processes and functions that are of interest to management.

For example, the STM for the Sandy Loam 12-16-inch Basin big sagebrush (Artemisia tridentata subsp. tridentata)/ bluebunch wheatgrass (Pseudoroegeneria spicata) ecological site in Idaho shows that improper grazing management (IGM in the model diagram) can cause a change from a reference community of basin big sagebrush and cool-season perennial bunchgrasses (phase A) to a depleted shrub community (phase B) within the reference state (State 1) by decreasing the cover of cool-season perennial grasses, leading to an increase in perennial grasses such as squirreltail (Elymus elymoides) and annual grasses including cheatgrass (Bromus tectorum). If grazing intensity is too high and fire occurs, a threshold can be crossed and the state can change to an annual grass state (State 2). The ways in which grazing affects the composition of plants in this ecological site suggest that the cover of perennial and annual grasses would be a useful indicator of impact from grazing.

Ecological site descriptions also aid in the interpretation of RMA data. The qualitative rangeland assessment method, "Interpreting Indicators of Rangeland Health" (IIRH) ${ }^{7}$ is built upon the idea that the values for indicators of soil stability, hydrologic function, and biotic integrity vary by ecological site. The IIRH indicators are judged based on a reference sheet that describes each indicator as it would occur under reference conditions (i.e., the reference phase in Bestelmeyer et al., this issue). The IIRH reference sheets, developed for each ecological site by experts having extensive knowledge of that site, are the benchmark for evaluating an ecological site using IIRH and necessary to interpret the 17 IIRH indicators. For example, in New Mexico, the IIRH reference sheet describes a shallow upland site ${ }^{\mathrm{ii}}$ in reference condition as being expected to have between 25\% and $35 \%$ cover of bare ground. An adjacent loamy upland site $\mathrm{i}^{\mathrm{iii}}$ in reference condition would be expected to have only $15 \%$ to $25 \%$ bare ground cover. Thus, in order to assess the condition of an area using the IIRH method, it is first necessary to identify its ecological site. Increasingly, ecological site descriptions include reference sheets that describe the characteristics of the site relative to the 17 indicators of rangeland health. ${ }^{7}$

' Ecological site ID: R010AY022ID. Available at: http://esis.sc.egov. usda.gov/ESDReport/fsReport.aspx?approved=no\&id=R010AY022ID. Accessed 6 October 2010.

"Ecological site ID: R070AY003NM. Available at: http://esis.sc.egov. usda.gov/ESDReport/fsReport.aspx?approved=yes\&id=R070AY003 NM. Accessed 6 October 2010.

iii Ecological site ID: R070AY001NM. Available at: http://esis.sc.egov. usda.gov/ESDReport/fsReport.aspx?approved=yes\&id=R070AY001 NM. Accessed 6 October 2010.
As an example, Miller $^{8}$ used the IIRH protocol to assess the status of three ecosystem attributes (soil stability, hydrologic function, and biotic integrity) across the 760,000-ha Grand Staircase-Escalante National Monument. There were 50 ecological sites described for the monument; from a sample of 507 locations, 26 ecological sites had more than five sample locations. The rating of the indicators against a reference sheet for each ecological site allowed Miller to combine the results across different ecological sites to draw conclusions about land status across the monument.

\section{Emerging Uses of Ecological Sites}

The current uses of ecological sites have greatly improved the ability to collect and interpret data for RMA. However, there are many more ways in which ecological sites can be used to improve both the efficiency and accuracy of RMA. These include using ecological site descriptions and their STMs to 1) help identify where monitoring should occur, 2) determine sampling intensity, 3) develop standard and consistent indicators of ecosystem attributes for RMA, 4) provide a context to support the use of remote-sensing techniques, and 5) develop a dynamic framework for managing rangelands in the context of climate change.

One of the biggest challenges in designing monitoring programs is deciding where to sample. This challenge occurs on two scales-selection of what portions of a landscape will be monitored and selection of specific sample locations within these larger areas. Ecological sites already are being used as an aid in selecting specific sample locations via stratification as illustrated above, but they also can be used to define which broader areas will be monitored. STMs can be used to determine the areas that are more or less likely to experience change in response to specific management activities or disturbances. Areas that are likely to experience change that could push them toward a threshold (i.e., state change) should be monitored at the highest intensity. Stable states (i.e., areas that already have crossed a threshold), or states that will not be affected by management, can be monitored at lower intensities (i.e., fewer sample locations).

This approach is being applied by BLM's Las Cruces District Office (LCDO) in southwest New Mexico for selecting locations for restoration of shrub-invaded grasslands and designing subsequent monitoring programs. Using a map of states and ecological sites (Fig. 3), BLM staff evaluated potential restoration locations based on the area covered by each state or community phase in each management area. ${ }^{9}$ Preference was given to areas that had phases experiencing shrub encroachment and that were hypothesized to experience increases in perennial grass cover (i.e., reference and shrub-dominated states). Little effort was put toward treating or monitoring areas in the shrubland state because they were not expected to experience significant increases in perennial grass cover.

The example above illustrates how ecological sites can be used to assist with the allocation of sampling effort. Intensity 


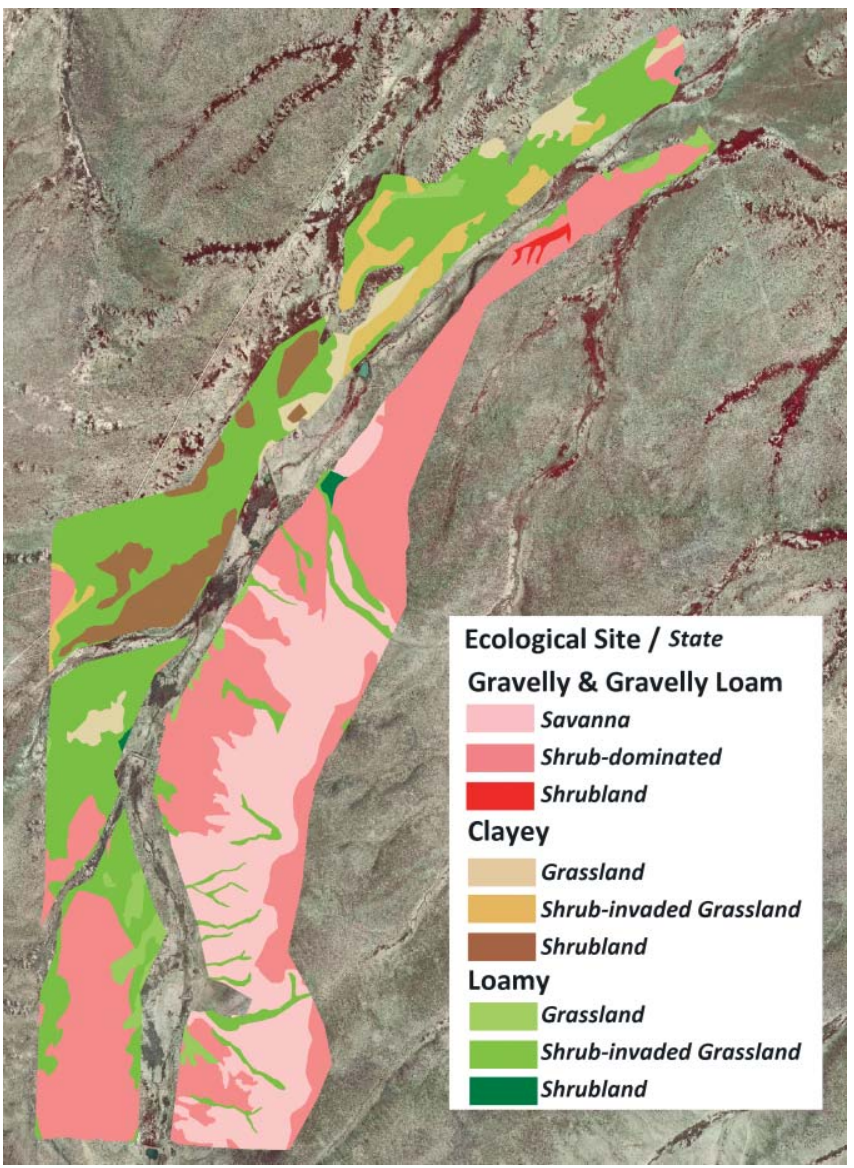

Figure 3. Example of a map of ecological sites and states within sites developed for the Bureau of Land Management's Las Cruces District Office in New Mexico. The geographic distribution of the states was used to select locations for shrub removal and monitoring of shrub encroachment based on the potential for the site to be restored to perennial grassland.

of sampling can vary among strata and should be determined by 1) magnitude of change to be detected, 2) variability within the stratum, and 3) the likelihood that the area will experience change. Typically, the desired minimum detectable change is set by management and monitoring objectives and logistical constraints, but also can be informed by the ecological site reference sheet and STM. A smaller minimum detectable change might be selected for strata that are expected to be affected by management activities. For example, BLM's LCDO might be interested in detecting a $50 \%$ change in perennial grass cover within reference states considered at risk of crossing a threshold. Alternatively, a high minimum detectable change might be acceptable for stable sites (e.g., 100\% change in perennial grass cover in the shrubland state might be acceptable because it is unlikely to experience change and if it does, managers would be only interested in large degrees of change). Site variability should be estimated using pilot data (stratified by ecological site) or existing data from a similar ecological site. For the majority of ecological sites and states, it currently is possible only to make qualitative judgments of potential sampling intensity from existing ecological site descriptions (i.e., determine whether sampling intensity should be higher or lower in one ecological site or state compared to another). However, because ecological site descriptions improve and quantitative data linked to them accumulate, stored ecological-site information might be used to assist in allocation of sampling effort.

Ecological sites also are being used in the development and implementation of standardized monitoring protocols. As the diversity of uses of public lands and the threats to land condition (e.g., fire, invasive species, erosion) have increased, it has become apparent that monitoring for individual species (e.g., sage grouse [Centrocercus urophasianus]), uses (e.g., grazing), and threats alone is not effective and does not provide the flexibility needed to respond to new monitoring objectives as they develop. Combining different monitoring efforts to address multiple needs is desirable, but the lack of standardized methods and sample design has prevented this to date. Because they are based on site potential and have explicit links to management and disturbance activities, ecological sites make an ideal foundation for building a nationwide sampling framework that can support low-intensity national-level sampling (e.g., NRCS Natural Resources Inventory) as well as integrate more intensive, fine-scale sampling to meet local management needs. The BLM's Assessment, Inventory, and Monitoring Strategy project is currently developing such a system based on ecological sites. ${ }^{10}$

Remote sensing is playing an increasingly important role in RMA. Its use will continue to grow as more sophisticated techniques are employed and reliable products are developed across a wide range of spatial scales. In rangeland systems, soil-surface reflectance can have a large influence on image sensor measurements and make it difficult to discriminate between vegetation types or amounts. Similar to their utility for stratification of field-based surveys, ecological sites can improve remote-sensing classification by identifying and isolating areas where soil reflectance is expected to be similar. More generally, ecological site descriptions can be a helpful starting point for defining land cover classes that are relevant to management objectives and that can be reliably mapped. Similar to field-based indicators, remotely-sensed indicators of rangeland ecosystems are of limited utility to management objectives. Ecological sites provide the context necessary to translate the results of remotely-sensed products into actionable management information.

Finally, ecological sites can be used to create a dynamic framework for managing land use in the context of climate change. Ecological site descriptions and their STMs convey the possible outcomes of different land uses based largely on information from the recent past. As temperature and precipitation regimes change, plant communities and land use effects on them will change. This will necessitate a periodic refreshing of ecological site descriptions and continuing research into ecological site dynamics. Nonetheless, ecological 
site databases provide a mechanism for documenting the structural and functional changes to rangeland ecosystems into the future, and allow for managers to evaluate the potential impacts of existing and new land uses.

The Landscape Toolbox project (www.landscapetoolbox. org) was developed to support these emerging uses of ecological sites and to integrate different tools and techniques for RMA. The Landscape Toolbox builds on the framework in Figure 1 and recognizes the importance of scale in understanding and managing natural systems. The appropriate scale for RMA will be determined by the management objective and the system being managed, and the best combination of indicators, tools, and techniques for RMA (including uses of ecological sites and STMs) will vary with scale. The Landscape Toolbox provides techniques for selecting scales for RMA and tools and information sources (e.g., the Rangeland Assessment and Monitoring Methods Guide, www.rangelandmethods.org) on many different RMA methods and how they can be used together.

\section{Conclusion}

Ecological site concepts and existing ecological site data products (e.g., ecological site descriptions, STMs, spatial data layers) are useful for RMA on many levels, from organizing our understanding of natural systems to aiding in sample design and interpreting data. We discussed only a subset of the possible uses of ecological site concepts in RMA. For applications such as sample stratification or rangeland health reference sheets, ecological sites already are widely used. However, the potential for ecological sites to improve the efficiency, sensitivity, and validity of RMA is much greater than currently realized. Achieving this potential will require the continued development of data products (e.g., periodically revised ecological site descriptions, more complete STMs, and spatially explicit data on states and phases) and better and more timely mechanisms for delivering those products to users.

\section{References}

1. US Department of Agriculture. 1997. Natural Resources Conservation Service, National range and pasture handbook. Washington, DC, USA: USDA, NRCS, Grazing Lands Technology Institute. 573 p.

2. Bestelmeyer, B. T., A. J. Tugel, G. L. Peacock, Jr., D. G. Robinett, P. L. Shaver, J. R. Brown, J. E. Herrick, H.
Sanchez, and K. M. Havstad. 2009. State-and-transition models for heterogeneous landscapes: a strategy for development and application. Rangeland Ecology \& Management 62:115.

3. Herrick, J. E., B. T. Bestelmeyer, S. Archer, A. J. Tugel, And J. R. Brown. 2006. An integrated framework for sciencebased arid land management. Journal of Arid Environments 65:319-335.

4. Winthers, E., D. Fallon, J. Haglund, T. DeMeo, G. Nowacki, D. Tart, M. Ferwerda, G. Robertson, A. Rorick, D. T. Cleland, and W. Robbie. 2005. Terrestrial ecological unit inventory technical guide. Washington, DC, USA: USDA Forest Service, Washington Office, Ecosystem Management Coordination Staff. 254 p.

5. Briske, D. D., S. D. Fuhlendorf, and F. E. Smeins. 2005. State-and-transition models, thresholds, and rangeland health: a synthesis of ecological concepts and perspectives. Rangeland Ecology Eं Management 58:1-10.

6. Briske, D. D., S. D. Fuhlendorf, and F. E. Smeins. 2006. A unified framework for assessment and application of ecological thresholds. Rangeland Ecology \& Management 59:225-236.

7. Pellant, M., P. Shaver, D. A. Pyke, and J. E. Herrick. 2005. Interpreting indicators of rangeland health Version 4. Denver, CO: USA: US Department of the Interior, Bureau of Land Management, National Science and Technology Center. $123 \mathrm{p}$.

8. Miller, M. E. 2008. Broad-scale assessment of rangeland health, Grand Staircase-Escalante National Monument, USA. Rangeland Ecology \& Management 61:249-262.

9. Bestelmeyer, B. T., X. B. Wu, J. R. Brown, S. D. FuhlenDORF, AND G. Fults. In press. Landscape approaches to rangeland conservation practices. In: D. D. Briske [ED.]. Conservation Benefits of Rangeland Practices: Assessment, Recommendations, and Knowledge Gaps. Lawrence, KS, USA: Allen Press.

10. Karl, J. W., J. E. Herrick, M. Eaton, and C. Mackinnon. 2010. Uses and benefits of consistent indicators and scalable sample design for NLCS local-to-national data needs. In: M. Eaton and P. B. Landres [EDs.]. Decade of Discovery in the National Landscape Conservation System. Albuquerque, NM, USA: USDA Forest Service Rocky Mountain Research Station.

Authors are Postdoctoral Research Ecologist, jkar@@msu.edu (Karl) and Research Soil Scientist (Herrick), USDA-Agricultural Research Service Jornada Experimental Range, Las Cruces, NM 88003, USA. 